\title{
BMJ Open Geographical and ethnic differences of osteoarthritis-associated hip and knee replacement surgeries in New Zealand: a population-based cross-sectional study
}

$\overline{\text { Chunhuan Lao, }{ }^{1} \text { David Lees, }{ }^{2} \text { Sandeep Patel, }{ }^{3} \text { Douglas White, },{ }^{4,5} \text { Ross Lawrenson }{ }^{1,6}}$

To cite: Lao C, Lees D, Patel S, et al. Geographical and ethnic differences of osteoarthritisassociated hip and knee replacement surgeries in New Zealand: a population-based cross-sectional study. BMJ Open 2019;9:e032993. doi:10.1136/ bmjopen-2019-032993

- Prepublication history and additional material for this paper are available online. To view these files, please visit the journal online (http://dx.doi. org/10.1136/bmjopen-2019032993).

Received 15 July 2019 Revised 27 August 2019 Accepted 30 August 2019

Check for updates

(c) Author(s) (or their employer(s)) 2019. Re-use permitted under CC BY-NC. No commercial re-use. See rights and permissions. Published by BMJ.

${ }^{1}$ Waikato Medical Research Centre, University of Waikato, Hamilton, New Zealand ${ }^{2}$ Orthopaedic Department, Tauranga Hospital, Tauranga, New Zealand

${ }^{3}$ Orthopaedic Department, Waikato Hospital, Hamilton, New Zealand

${ }^{4}$ Rheumatology Department, Waikato District Health Board, Hamilton, New Zealand ${ }^{5}$ Waikato Clinical School, The University of Auckland, Auckland, New Zealand

${ }^{6}$ Strategy and Funding, Waikato District Health Board, Hamilton, New Zealand

Correspondence to

Dr Chunhuan Lao;

chunhuan.lao@waikato.ac.nz

\section{ABSTRACT}

Objectives To (1) explore the regional and ethnic differences in rates of publicly funded osteoarthritisassociated hip and knee replacement surgeries and (2) investigate the mortality after surgery.

Design Population-based, retrospective, cross-sectional study.

Setting General population in New Zealand.

Participants Patients with osteoarthritis who underwent publicly funded primary hip and knee replacement surgeries in 2005-2017. Patients aged 14-99 years were included.

Primary and secondary outcome measures Agestandardised rate, standardised mortality ratio (SMR) and 30 days, 90 days and 1 year mortality.

Results We identified 53439 primary hip replacements and 50072 primary knee replacements with a diagnosis of osteoarthritis. The number and age-standardised rates of hip and knee replacements increased over time. Māori had the highest age-standardised rate of hip replacements, followed by European/others and Pacific, and Asian had the lowest rate. Pacific had the highest age-standardised rate of knee replacements, followed by Māori and European/others, and Asian had the lowest rate. The Northern Health Network had the lowest rate of hip surgeries, and the Southern Health Network had the lowest rate of knee surgeries. The SMRs of patients undergoing hip and knee replacements were lower than the general population: 0.92 (95\% Cl 0.89 to 0.95 ) for hip and 0.79 (95\% Cl 0.76 to 0.82 ) for knee. The SMRs were decreasing over time. The patterns of 30 days, 90 days and 1 year mortality were similar to the SMR.

Conclusions The numbers of publicly funded osteoarthritis-associated primary hip and knee replacements are steadily increasing. Māori people had the highest age-standardised rate of hip replacements and Pacific people had the highest rate of knee replacements. The Northern Health Network had the lowest rate of hip surgeries, and the Southern Health Network had the lowest rate of knee surgeries. Compared with the general population, patients who had hip and knee replacements have a better life expectancy.

\section{INTRODUCTION}

Osteoarthritis is the most common form of arthritis. In New Zealand, osteoarthritis affects $10.6 \%$ of adults. ${ }^{1}$ European people
Strengths and limitations of this study

- This study is based on national data sets including over 100000 primary hip and knee replacement surgeries, with comprehensive data on patient characteristics, comorbidities and mortality.

- We used the WHO standard population as the reference to calculate the age-standardised rates of primary hip and knee replacement surgeries, to enable international comparisons on age-standardised rates of surgeries.

- We estimated the 30 days, 90 days and 1 year mortality after surgery, as well as standardised mortality ratio (SMR), which is easier for global comparison.

- Poisson regression modelling was used to calculate the rate ratios of SMR by subgroup after adjustment for other factors.

- One weakness is that this study does not have data on the prevalence of hip and knee osteoarthritis by subgroups to identify the reasons for lower rates of surgeries in some subgroups.

are more likely to have $(12.5 \%)$ osteoarthritis than Māori $(7.1 \%)$, Pacific $(4.8 \%)$ and Asian people (2.5\%). ${ }^{1}$ Risk factors of osteoarthritis include systemic factors (such as genetics, dietary intake, oestrogen use and bone density) and local biomechanical factors (such as muscle weakness, obesity, occupation factors, sports participation and joint laxity). ${ }^{2}$ These risk factors partially explain the ethnic differences in prevalence of osteoarthritis.

Osteoarthritis of the hip and knee is one of the most common causes of reduced mobility. Hip and knee replacements for osteoarthritis can help to alleviate pain and improve function. The New Zealand Joint Registry (NZJR) reported osteoarthritis as the indication for $87 \%$ and $84 \%$ of primary hip and knee arthroplasties, respectively. ${ }^{4}$ Regional and ethnic disparities in hip and knee replacement surgeries have been demonstrated in other countries. ${ }^{5-12}$ It has been reported in 
Australia that total hip and knee replacements are more likely to be performed for socially advantaged populations. ${ }^{13} 14$ African-Americans, Asians and Hispanics are less likely to receive hip and knee replacement surgeries than American-European. ${ }^{5}{ }^{12}$ Some studies have found variations in practice between different regions in New Zealand, ${ }^{15-18}$ but little has been reported in the differences in access to hip and knee replacement surgeries between different regions.

Perioperative mortality is of great importance for assessing the safety of interventions, undertaking performance assessment and completing quality improvement initiatives. ${ }^{19}{ }^{20}$ Hip and knee replacement surgeries are generally considered to be safe and successful procedures. Short-term and long-term mortality after hip and knee replacements has been reported to be lower or equivocal to the general population. ${ }^{21-25}$

The New Zealand healthcare system is a mix of government-funded and private healthcare. The public-funded system is controlled and managed by the Ministry of Health. ${ }^{26}$ The District Health Boards (DHBs) hold $75 \%$ of health funding in New Zealand. The public resources are limited and are allocated based on prioritisation. ${ }^{27}$ Before 2017, the DHBs uses a clinical priority system specific to hip and knee primary and revision surgery for prioritising patients for surgery. ${ }^{28}$ Since around 2017, the DHBs have shifted to using a generic prioritisation tool called Clinical Priority Assessment Criteria. ${ }^{29}$ While the same scoring tool is used between DHBs, the score required to meet the commitment threshold is determined by individual DHBs, so varies between regions. It may be adjusted throughout the year based on available resources.

This study aims to (1) explore the regional and ethnic differences in rates of publicly funded osteoarthritis-associated hip and knee replacement surgeries and (2) investigate the mortality of patients having hip and knee replacement surgeries.

\section{METHODS}

\section{Data sources}

This study included patients with osteoarthritis who underwent publicly funded primary hip and knee replacement surgeries in 2005-2017. Patients aged between 14 and 99 years were included. These records were identified from the National Minimum Dataset (NMD) that stores all publicly funded and some privately funded hospital inpatient and day-patient discharge information nationally. The ICD-10-AM ACHI procedure codes (V.3) were used to extract the primary hip and knee replacement surgeries. These records were cross-referenced with the NZJR data to exclude the admissions not for primary hip or knee replacement surgery.

The NMD records patient's diagnosis for the admission and other comorbidities with a maximum of 30 diagnostic codes. Patients without a diagnosis of osteoarthritis were excluded. Comorbidities for calculating the Charlson Comorbidity Index score were identified from the diagnostic codes based on the coding algorithms developed by Quan et $a l^{30}$

Data from the NMD were linked to the Mortality Collection through patients' National Health Index (NHI) numbers. ${ }^{31}$ The NHI number is a unique identifier that is assigned to every person who uses health and disability support services in New Zealand. The combined data sets included: (1) demographic information: age, gender, ethnicity and location (DHBs); (2) treatment information: diagnosis, comorbidities and date of surgery; and (3) date of death.

\section{Data analyses}

Age-standardised rates of primary hip and knee replacement surgeries by gender, ethnicity (Māori, Pacific, Asian and European/others) and regional health network were calculated using the WHO standard population as the reference. There are four health networks in New Zealand: Northern Health Network, Midland Health Network, Mid Central Health Network and Southern Health Network. The Northern Health Network has a high Pacific population, the Midland Health Network has a high Māori population and is very rural, and the Southern Health Network is also rural but with low Māori and Pacific populations. ${ }^{32} 33$

Because the population data by ethnicity and region provided by the Ministry of Health and Statistics New Zealand $^{33}$ was only available since 2006, the age-standardised rates by ethnicity and region were calculated for records in 2006-2017. Time trend analysis was performed on the number of surgeries as well as the age-standardised rates by subgroups.

Standardised mortality ratio (SMR) was estimated to compare the relative rate of observed deaths in the surgery group to expected deaths in the general population. The gender-specific, age-specific and year-specific mortality rate for the general population were from the Statistics New Zealand. The last updated date of the Mortality Collection was 31 December 2015; therefore, SMR was only estimated for patients in 2005-2014 to ensure all patients had at least 1-year follow-up after surgery. Subgroup analyses on SMR were performed by gender, age, ethnicity, Charlson score, year of surgery, health network and number of same type of surgeries. For patients who had two hip/knee (same type) surgeries, the first surgery date was used to calculate the SMR. Poisson regression modelling was used to calculate the adjusted rate ratios of SMR by subgroup. We have also estimated the 30 days, 90 days and 1 year mortality after surgery, and examined the differences by subgroup. All data cleaning and analyses were performed in R V.3.5.0.

\section{Patient and public involvement}

There was no active involvement of patients or the public in the research questions, study design and data analyses. 


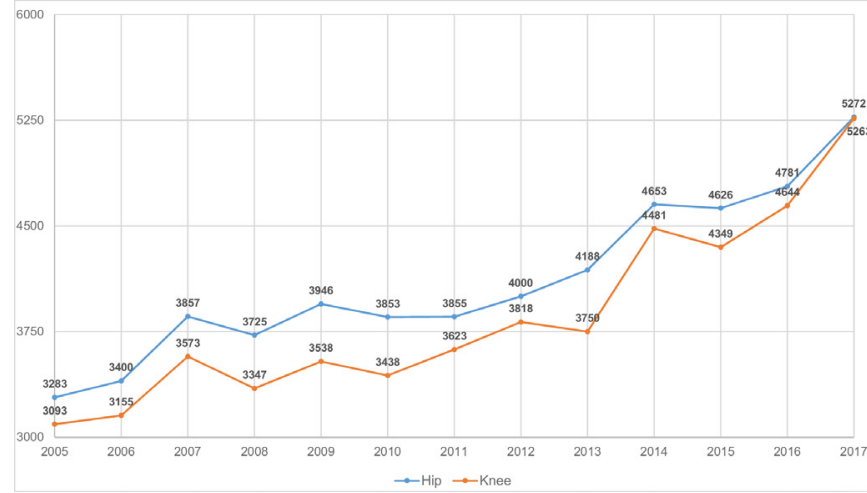

Figure 1 Number of publicly funded osteoarthritisassociated primary hip and knee replacements in 2005-2017.

\section{RESULTS}

We identified 60527 admissions for publicly funded primary hip replacements and 52098 admissions for primary knee replacements in 2005-2017 from the NMD. After cross-referencing with the NZJR, $500(0.8 \%)$ admissions coded for primary hip replacements and 483 $(0.9 \%)$ admissions coded for primary knee replacements were excluded. Of the eligible surgeries (60027 primary hip surgeries and 51615 primary knee surgeries), 53439 $(89.0 \%)$ primary hip replacements and $50072(97.0 \%)$ primary knee replacements had a diagnosis of osteoarthritis. The number of hip replacements has steadily increased from 3283 in 2005 to 5272 in 2017 (by 60.6\%), and the number of knee replacements increased from 3093 in 2005 to 5263 in 2017 (by 70.2\%) (figure 1). While more total hip than total knee replacement surgeries were performed in 2005, the total numbers of hip and knee replacement surgeries performed per year have converged over recent years.

The number of surgeries by ethnicity varied in different health network (appendix tables 1 and 2). For primary hip replacement surgeries, $17.4 \%$ of surgeries in the Midland Health Network were performed in Māori patients compared with only $4.3 \%$ in the Southern Health Network. For primary knee replacement surgeries, $10.0 \%$ of surgeries in the Northern Health Network were performed in Pacific patients compared with only $0.9 \%$ in the Southern Health Network and $1.6 \%$ in the Midland Health Network.

The overall age-standardised rates of hip and knee surgeries both increased over time (figures 2 and 3): from 59.7 per 100000 in 2005 to 69.8 per 100000 in 2017 for hips, and from 55.1 to 68.1 per 100000 for knees, respectively. The rates of hip and knee replacement surgeries between women and men were similar. There were great ethnic disparities in rates of hip and knee replacement surgeries. Māori had the highest age-standardised rate of hip surgeries (105.6 per 100000 in 2017), followed by European/others (74.0 per 100 000) and Pacific (30.0 per 100000 ), and Asian (5.3 per 100 000) had the lowest rate. Pacific had the highest age-standardised rate of knee replacements (108.9 per 100000 in 2017), followed
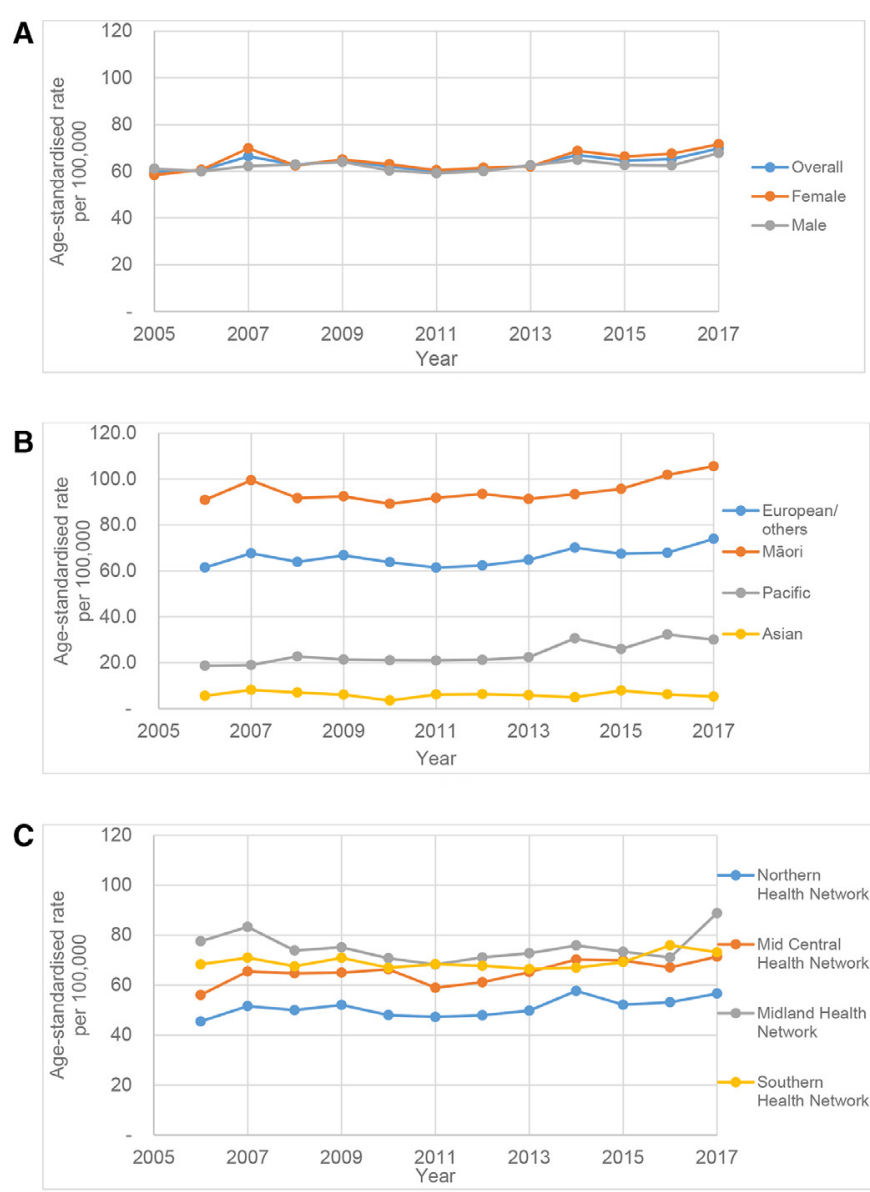

Figure 2 Age-standardised rates of primary hip replacement surgeries by subgroup: (A) overall and by gender; $(B)$ by ethnicity; (C) by health network.

by Māori (72.5 per 100 000) and European/others (68.5 per 100 000), Asian (39.3 per 100 000) had the lowest rate. The Northern Health Network had the lowest rate of hip surgeries, and the Southern Health Network had the lowest rate of knee surgeries.

Patients undergoing hip and knee surgeries had a longer life expectancy compared with the general population of the same gender and age in recent years. The SMRs of patients undergoing hip and knee surgeries were 0.92 and 0.79 , respectively (table 1 ). The SMRs were decreasing over time, from 1.05 (95\% CI 0.97 to 1.13 ) in 2005 to 0.62 (95\% CI 0.47 to 0.81 ) in 2014 for hip surgeries, and from 0.94 (95\% CI 0.87 to 1.01$)$ in 2005 to 0.46 (95\% CI 0.33 to 0.63 ) in 2014 for knee surgeries. Women had a lower SMR than men and patients aged $70+$ years had lower SMRs than younger patients, in terms of both hip and knee surgeries. The SMRs increased with Charlson score, from 0.70 for patients with a Charlson score 0 to 2.37 for patients with a Charlson score 3+ for hip surgery, and from 0.70 for Charlson score 0 to 1.93 for Charlson score 3+ for knee surgery. Māori patients undergoing hip and knee surgeries had a shorter life expectancy than the general population ( $\mathrm{SMR}>1$ ), but all other ethnic groups had a longer life expectancy than the general population $(\mathrm{SMR}<1)$. Patients in the Northern Health Network had 
A

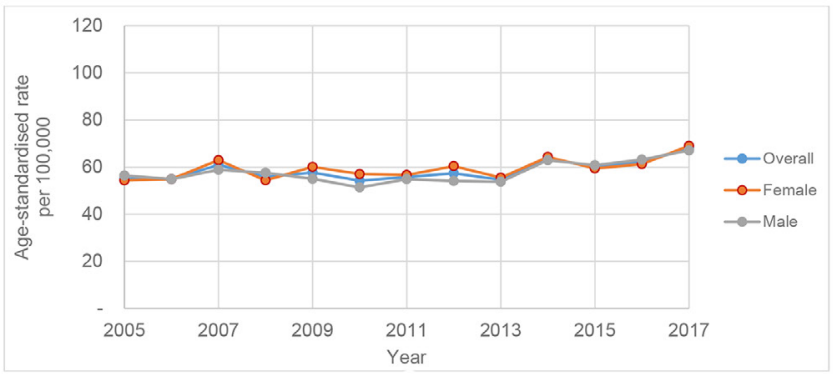

B

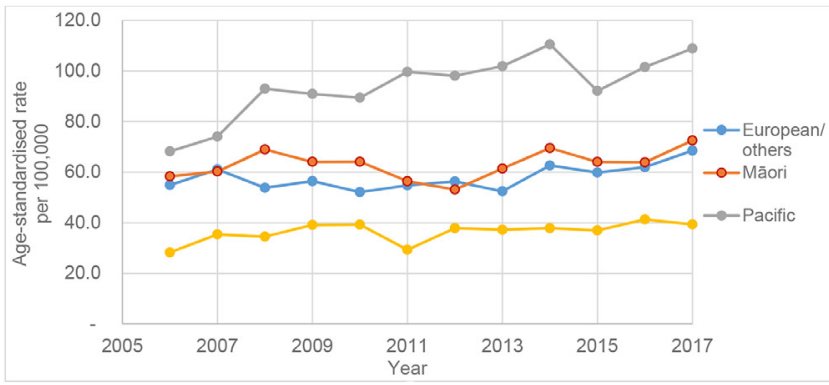

C

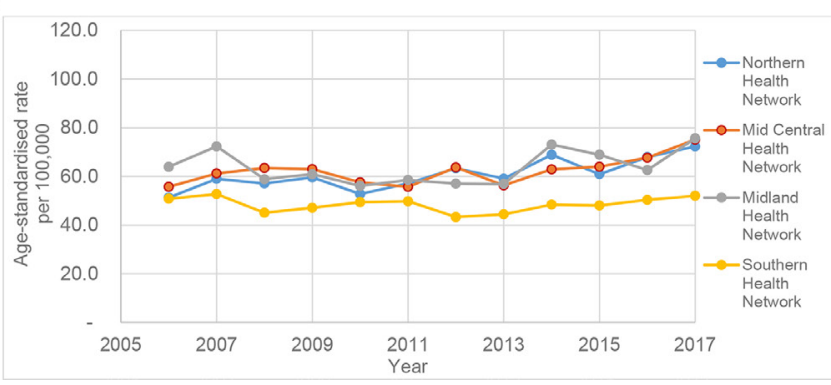

Figure 3 Age-standardised rates of primary knee replacement surgeries by subgroup: $(A)$ overall and by gender; (B) by ethnicity; (C) by health network.

the lowest SMR. Patients who had two hip/knee surgeries had a much lower SMR (0.57 and 0.52) than patients who only had one hip/knee surgery (0.98 and 0.87 ).

Poisson regression (table 2) showed that the adjusted rate ratio of SMR between men and women was $0.96(95 \%$ CI 0.91 to 1.02) for hip replacements and 1.03 (95\% CI 0.97 to 1.10 ) for knee replacements. Māori patients had a higher rate ratio of SMR compared with other ethnic groups, and all other health networks had high rate ratios $(>1)$ compared with the Northern Health Network. The rate ratio decreased with age and year, and increased with Charlson score.

The patterns of 30 days, 90 days and 1 year mortality after replacement surgery (appendix tables 3 and 4 ) by gender, Charlson score, year and number of surgeries were consistent with the SMR. The 30 days, 90 days and 1 year mortality all increased with age.

\section{DISCUSSION}

Among the total numbers of publicly and privately funded primary hip and knee replacements in 20052016, publicly funded primary hip and knee replacements accounted for $54 \%$ and $59 \%$, respectively. ${ }^{4}$ The annual proportion of publicly funded surgeries over the total public and private surgeries has been stable. The total number of publicly funded hip and knee replacements has been increasing over time as have the age-standardised rates of surgery.

In a paper by Pabinger and Geissler comparing the utilisation rates of hip replacements among 27 OECD (Organisation for Economic Co-operation and Development) countries, ${ }^{34}$ New Zealand ranked 17th in 2011 with a rate of 141 hip replacements per 100000 total population, and Switzerland had the highest rate of 306 per 100000 , followed by Germany (286 per 100 000) and Austria (273 per 100 000). The rates in this paper were not age-standardised and included all publicly and privately funded surgeries. These explained the difference between the rate of 141 per 100000 in Pabinger's paper and the age-standardised rate of 60 per 100000 in our study. Hooper $e t a l^{35}$ estimated an age-standardised rate of total hip and knee replacements of 285 and 250 per 100000 , respectively, in 2011 in New Zealand. The gaps between Hooper's and our estimations can be explained by all publicly and privately funded surgeries included in their study and the population used for estimating age-standardised rate, only including people aged 35+ years. We decided to use the WHO standard population including all age groups as the reference, because the Ministry of Health reports all use the WHO standard population to calculate the age-standardised rates and it enables head-to-head comparisons with overseas studies.

Interestingly, we found that Māori people had the highest age-standardised rate of publicly funded hip surgeries and Pacific people had the highest rate of publicly funded knee surgeries. Hooper's study showed that New Zealand Europeans had the highest rate of hip replacements and a second-highest rate of knee replacements, which was slightly lower than Pacific people. ${ }^{35}$ This is possibly because New Zealand Europeans are more likely to have privately funded surgeries than other ethnic groups. ${ }^{36}$ Asian people had the lowest rate of hip (less than $10 \%$ the rate for all patients) and knee (58\% of the rate for all patients) surgeries. This corresponds to the low prevalence of osteoarthritis for Asian people (1.9\%). ${ }^{1}$

The Northern Health Network had the lowest rate of hip surgeries, and has a high urban population compared with the other regions. Research has shown that farmers have high rates of hip osteoarthritis, ${ }^{37}$ and the Northern Health Network has a smaller population of rural residents than other health networks. The Southern Health Network had the lowest rate of knee surgeries. This may be related to the access problems. The Southern Health Network has a big rural population but low Māori and Pacific populations who had high needs of primary knee replacement surgeries as shown in our results. Other reasons may include the variations in the distribution of different ethnicities and people of different socioeconomic status in different health network. Socially disadvantaged populations are more likely to have better 
Table 1 Standardised mortality ratio (SMR) of studied patients compared with general population

\begin{tabular}{|c|c|c|c|c|}
\hline \multirow[b]{2}{*}{ Subgroups } & \multicolumn{2}{|c|}{ Primary hip replacement } & \multicolumn{2}{|c|}{ Primary knee replacement } \\
\hline & Number of patients & SMR $(95 \% \mathrm{Cl})$ & Number of patients & SMR $(95 \% \mathrm{Cl})$ \\
\hline \multicolumn{5}{|l|}{ Gender } \\
\hline Female & 18336 & 0.90 (0.86 to 0.95$)$ & 16205 & 0.76 (0.72 to 0.81$)$ \\
\hline Male & 15797 & 0.93 (0.89 to 0.98$)$ & 14136 & $0.82(0.78$ to 0.86$)$ \\
\hline \multicolumn{5}{|l|}{ Ethnicity } \\
\hline European/others & 29853 & 0.88 (0.84 to 0.91$)$ & 25692 & $0.77(0.74$ to 0.80$)$ \\
\hline Māori & 3671 & 1.64 (1.43 to 1.89$)$ & 2317 & 1.41 (1.20 to 1.66$)$ \\
\hline Pacific & 419 & 1.02 (0.62 to 1.68$)$ & 1345 & 0.76 (0.58 to 1.00$)$ \\
\hline Asian & 190 & 0.95 (0.51 to 1.80$)$ & 987 & $0.58(0.44$ to 0.78$)$ \\
\hline \multicolumn{5}{|l|}{ Age (years) } \\
\hline$<40$ & 518 & 1.81 (0.48 to 6.89$)$ & 52 & 4.72 (0.18 to 127.22$)$ \\
\hline $40-49$ & 2127 & 1.32 (0.84 to 2.06$)$ & 719 & 1.35 (0.63 to 2.92$)$ \\
\hline $50-59$ & 5515 & 1.37 (1.13 to 1.66$)$ & 4681 & 1.11 (0.90 to 1.38$)$ \\
\hline $60-69$ & 9924 & 1.12 (1.02 to 1.23$)$ & 10144 & 0.88 (0.80 to 0.97$)$ \\
\hline $70-79$ & 11300 & 0.84 (0.80 to 0.89$)$ & 10928 & 0.74 (0.70 to 0.78$)$ \\
\hline $80+$ & 4749 & 0.88 (0.83 to 0.93$)$ & 3817 & 0.79 (0.75 to 0.84$)$ \\
\hline \multicolumn{5}{|c|}{ Charlson Comorbidity Index } \\
\hline 0 & 29663 & 0.79 (0.76 to 0.82$)$ & 25538 & 0.70 (0.67 to 0.73$)$ \\
\hline 1 & 2236 & 1.37 (1.24 to 1.52$)$ & 2260 & 1.17 (1.05 to 1.30$)$ \\
\hline 2 & 1598 & 1.68 (1.45 to 1.95$)$ & 1874 & 1.12 (0.96 to 1.30$)$ \\
\hline $3+$ & 636 & 2.37 (1.97 to 2.85 ) & 669 & 1.93 (1.59 to 2.35$)$ \\
\hline \multicolumn{5}{|l|}{ Year } \\
\hline 2005 & 3176 & 1.05 (0.97 to 1.13$)$ & 2970 & 0.94 (0.87 to 1.01$)$ \\
\hline 2006 & 3149 & 1.04 (0.96 to 1.13$)$ & 2835 & 0.86 (0.79 to 0.94$)$ \\
\hline 2007 & 3520 & 0.97 (0.90 to 1.06$)$ & 3109 & 0.84 (0.76 to 0.92$)$ \\
\hline 2008 & 3312 & 0.98 (0.89 to 1.08$)$ & 2828 & 0.79 (0.71 to 0.88$)$ \\
\hline 2009 & 3473 & 0.87 (0.78 to 0.97 ) & 3009 & 0.84 (0.75 to 0.95$)$ \\
\hline 2010 & 3356 & 0.79 (0.70 to 0.90$)$ & 2849 & 0.66 (0.58 to 0.76$)$ \\
\hline 2011 & 3305 & 0.75 (0.65 to 0.87 ) & 2981 & 0.68 (0.58 to 0.80$)$ \\
\hline 2012 & 3426 & 0.72 (0.60 to 0.85$)$ & 3097 & 0.49 (0.40 to 0.61$)$ \\
\hline 2013 & 3541 & 0.63 (0.50 to 0.78$)$ & 3020 & 0.47 (0.36 to 0.60$)$ \\
\hline 2014 & 3875 & 0.62 (0.47 to 0.81$)$ & 3643 & 0.46 (0.33 to 0.63$)$ \\
\hline \multicolumn{5}{|l|}{ Health network } \\
\hline Northern & 8956 & 0.90 (0.83 to 0.96$)$ & 9996 & 0.72 (0.67 to 0.77 ) \\
\hline Mid Central & 7040 & 0.96 (0.89 to 1.04$)$ & 6448 & 0.82 (0.75 to 0.89$)$ \\
\hline Midland & 8308 & 0.94 (0.88 to 1.01$)$ & 6834 & 0.84 (0.78 to 0.91$)$ \\
\hline Southern & 9807 & 0.88 (0.83 to 0.95$)$ & 7046 & 0.83 (0.77 to 0.89$)$ \\
\hline Unknown & 22 & 1.21 (0.25 to 5.84$)$ & 17 & 0.47 (0.05 to 4.65$)$ \\
\hline \multicolumn{5}{|c|}{ Number of same type of surgeries in $2005-2017$} \\
\hline 1 & 28804 & 0.98 (0.94 to 1.02$)$ & 24128 & 0.87 (0.83 to 0.91$)$ \\
\hline 2 & 5329 & 0.57 (0.51 to 0.64$)$ & 6213 & 0.52 (0.47 to 0.57 ) \\
\hline Total & 34133 & 0.92 (0.89 to 0.95$)$ & 33825 & 0.79 (0.76 to 0.82$)$ \\
\hline
\end{tabular}


Open access

Table 2 Rate ratios of standardised mortality ratio from Poisson regression model

\begin{tabular}{|c|c|c|c|c|c|c|}
\hline \multirow[b]{2}{*}{ Variables } & \multicolumn{3}{|c|}{ Primary hip replacements } & \multicolumn{3}{|c|}{ Primary knee replacements } \\
\hline & Rate ratio & $95 \% \mathrm{Cl}$ & $P$ value & Rate ratio & $95 \% \mathrm{Cl}$ & $P$ value \\
\hline \multicolumn{7}{|l|}{ Gender } \\
\hline Male & 0.96 & 0.91 to 1.02 & 0.216 & 1.03 & 0.97 to 1.10 & 0.308 \\
\hline \multicolumn{7}{|l|}{ Ethnicity } \\
\hline Māori & 1.61 & 1.46 to 1.78 & $<0.001$ & 1.71 & 1.52 to 1.92 & $<0.001$ \\
\hline Pacific & 0.96 & 0.67 to 1.39 & 0.829 & 0.98 & 0.79 to 1.22 & 0.883 \\
\hline Asian & 1.00 & 0.62 to 1.61 & 0.997 & 0.78 & 0.61 to 0.99 & 0.045 \\
\hline \multicolumn{7}{|l|}{ Age (years) } \\
\hline$<40$ & Ref & & & Ref & & \\
\hline $60-69$ & 0.60 & 0.27 to 1.34 & 0.213 & 0.21 & 0.05 to 0.83 & 0.026 \\
\hline $70-79$ & 0.45 & 0.20 to 0.99 & 0.048 & 0.17 & 0.04 to 0.68 & 0.012 \\
\hline $80+$ & 0.46 & 0.21 to 1.03 & 0.060 & 0.18 & 0.05 to 0.73 & 0.016 \\
\hline
\end{tabular}

Charlson Comorbidity Index

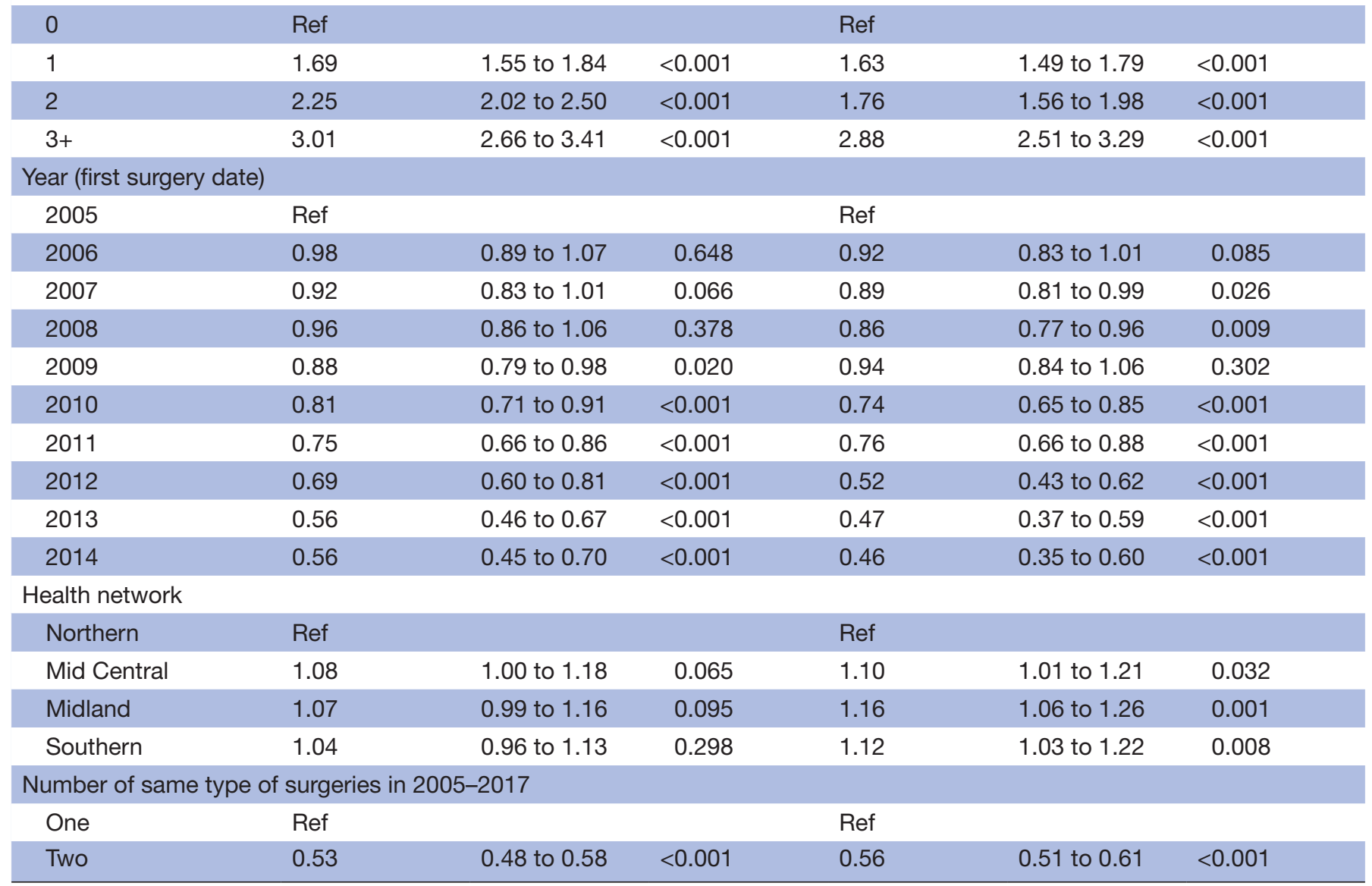

Ref, reference. 
access to hip and knee replacements compared with their less disadvantaged counterparts. ${ }^{13} 14$

This study showed that patients who had primary hip and knee replacement surgeries had longer life expectancy than the general population $(\mathrm{SMR}<1)$. This again confirms that hip and knee replacement surgeries are safe and successful procedures. This is consistent with findings from other studies ${ }^{21} 222425$ reporting better mortality following total hip and knee replacements than the general population, although individuals with osteoarthritis have a shorter life expectancy. ${ }^{23}$ Possible explanations include selection of healthier individuals to undergo surgery and benefits of increased mobility and activity levels after surgery. ${ }^{22} 25$

The high SMR and rate ratio (from Poisson regression) for Māori patients can be attributed to the overall shorter life expectancy for Māori ${ }^{38}$ and the SMR was calculated by comparing Māori with the general population. The gender-specific, age-specific and year-specific mortality rate by different ethnic populations were not available. This also explains why the Midland Health Network that has the highest proportion of Māori patients $(15 \%$ vs $4 \%-10 \%$ in other health networks) had the highest SMR. For hip replacement surgeries, 19\% of Māori patients had a Charlson score of 1+ compared with $12 \%$ of European/others, and for knee replacements, 23\% of Māori patients had a Charlson score of $1+$ compared with $14 \%$ of European/others.

Mortality declined with increasing age at surgery, which was reported in previous studies assuming younger patients may have more comorbidities and higher risk of death. ${ }^{22}{ }^{25}$ In our cohort, $5 \%$ of patients aged less than 50 years had one or more comorbidities. Other investigators observed a convergence of mortality after 5 years following surgery. ${ }^{39} 40$ This corresponds to the similar mortality to the general population (SMR close to 1 ) for patients having surgeries in 2005-2008.

The strength of this study is that it is based on national data sets including over 100000 primary hip and knee replacement surgeries. These data sets collect comprehensive data on patient characteristics, comorbidities and mortality. One weakness is that this study does not have data on the prevalence of hip and knee osteoarthritis by subgroups. Therefore, we cannot ascertain whether the lower rates of surgeries in some subgroups (eg, lower rates of hip surgeries in Pacific and Asian people) was because of the lower prevalence of hip and knee osteoarthritis in these subgroups or barriers of access to public health services. The mortality data were only available till 31 December 2015, and we could not examine the mortality of patients in 2015-2017.

\section{CONCLUSIONS}

The numbers of publicly funded osteoarthritis-associated primary hip and knee replacement surgeries are steadily increasing. Māori people had the highest age-standardised rate of publicly funded primary hip replacements and
Pacific people had the highest rate of publicly funded knee replacements. The Northern Health Network had the lowest rate of hip surgeries, and the Southern Health Network had the lowest rate of knee surgeries. Compared with the general population, patients who had hip and knee replacements had a better life expectancy.

Acknowledgements We would like to thank the New Zealand Joint Registry for providing the data for validation.

Contributors CL, DL, RL, DW and SP conceived of and designed the study. CL did all the data cleaning and analyses, and wrote the first draft of the main paper. All the authors discussed the results and were involved in the critical revisions of the manuscript. All the authors have read and approved the final version of the manuscript.

Funding This study was funded by the Lottery Health Research (project number: 106082).

Disclaimer This study was funded by the Lottery Health Research (project number: 106082). The funder was not involved in any part of this study.

Competing interests None declared.

Patient consent for publication Not required.

Ethics approval Ethical approval for the study was granted through the Central Health and Disability Ethics Committee, reference: 17/CEN/124.

Provenance and peer review Not commissioned; externally peer reviewed.

Data availability statement No data are available.

Open access This is an open access article distributed in accordance with the Creative Commons Attribution Non Commercial (CC BY-NC 4.0) license, which permits others to distribute, remix, adapt, build upon this work non-commercially, and license their derivative works on different terms, provided the original work is properly cited, appropriate credit is given, any changes made indicated, and the use is non-commercial. See: http://creativecommons.org/licenses/by-nc/4.0/.

\section{REFERENCES}

1. Ministry of Health. Annual data explorer 2017/18: new Zealand health survey Wellington, New Zealand, 2019. Available: https:// minhealthnz.shinyapps.io/nz-health-survey-2017-18-annual-dataexplorer/_w_0811ceee/_w_e98adb87/\#!/home [Accessed 26 Jun 2019].

2. Felson DTet al. Osteoarthritis: new insights. Part 1: the disease and its risk factors. Ann Intern Med 2000;133:635-46.

3. Andersen S, Thygesen LC, Davidsen M, et al. Cumulative years in occupation and the risk of hip or knee osteoarthritis in men and women: a register-based follow-up study. Occup Environ Med 2012;69:325-30.

4. New Zealand Orthopaedic Association. The New Zealand joint registry 17 year report. Wellington, New Zealand, 2016.

5. Chen J, Rizzo JA, Parasuraman S, et al. Racial disparities in receiving total hip/knee replacement surgery: the effect of hospital admission sources. J Health Care Poor Underserved 2013;24:135-51.

6. Schäfer T, Pritzkuleit R, Jeszenszky C, et al. Trends and geographical variation of primary hip and knee joint replacement in Germany. Osteoarthritis Cartilage 2013;21:279-88.

7. Judge A, Welton NJ, Sandhu J, et al. Geographical variation in the provision of elective primary hip and knee replacement: the role of socio-demographic, hospital and distance variables. J Public Health 2009;31:413-22.

8. Dixon T, Shaw ME, Dieppe PA. Analysis of regional variation in hip and knee joint replacement rates in England using Hospital episodes statistics. Public Health 2006;120:83-90.

9. Dixon T, Urquhart DM, Berry P, et al. Variation in rates of hip and knee joint replacement in Australia based on socio-economic status, geographical locality, birthplace and Indigenous status. ANZ J Surg 2011;81:26-31.

10. Ibrahim SA. Racial variations in the use of knee and hip joint replacement: an introduction and review of the most recent literature. Curr Orthop Pract 2010;21:126-31.

11. Ibrahim SA. Racial/Ethnic variations in knee and hip elective joint replacement in the UK. Osteoarthritis and Cartilage 2017;25:435-7.

12. Hoaglund FT, Oishi CS, Gialamas GG. Extreme variations in racial rates of total hip arthroplasty for primary coxarthrosis: a populationbased study in San Francisco. Ann Rheum Dis 1995;54:107-10. 
13. Brennan-Olsen S, Vogrin S, Holloway KL, et al. Geographic region, socioeconomic position and the utilisation of primary total joint replacement for hip or knee osteoarthritis across Western Victoria: a cross-sectional multilevel study of the Australian orthopaedic association national joint replacement registry. Arch Osteoporos 2017;12:97.

14. Brennan SL, Stanford T, Wluka AE, et al. Utilisation of primary total knee joint replacements across socioeconomic status in the Barwon statistical division, Australia, 2006-2007: a cross-sectional study. BMJ Open 2012;2:e001310.

15. Blackett J, Carslaw A, Lees D, et al. The impact of the 6-month waiting target for elective surgery: a patient record study. $N Z \mathrm{Med} J$ 2014;127:45-53.

16. Pearce J, Dorling D. Increasing geographical inequalities in health in New Zealand, 1980-2001. Int J Epidemiol 2006;35:597-603.

17. Pearce J, Dorling D, Wheeler B, et al. Geographical inequalities in health in New Zealand, 1980-2001: the gap widens. Aust N Z J Public Health 2006;30:461-6.

18. Sheridan NF, Kenealy TW, Connolly MJ, et al. Health equity in the New Zealand health care system: a national survey. Int $J$ Equity Health 2011;10:45

19. Russell EM, Bruce J, Krukowski ZH. Systematic review of the quality of surgical mortality monitoring. Br J Surg 2003;90:527-32.

20. Hider P, Frampton C, Theis J-C, et al. Perioperative mortality in New Zealand related to hip and knee replacement surgery: comparing administrative and registry data. N Z Med J 2016;129:33-40.

21. Lie SA, Engesaeter LB, Havelin LI, et al. Mortality after total hip replacement: 0-10-year follow-up of 39,543 patients in the Norwegian arthroplasty register. Acta Orthop Scand 2000;71:19-27.

22. Robertsson $O$, Stefánsdóttir $A$, Lidgren $L$, et al. Increased long-term mortality in patients less than 55 years old who have undergone knee replacement for osteoarthritis: results from the Swedish knee arthroplasty register. J Bone Joint Surg Br 2007;89:599-603.

23. Nüesch $\mathrm{E}$, Dieppe $\mathrm{P}$, Reichenbach $\mathrm{S}$, et al. All cause and disease specific mortality in patients with knee or hip osteoarthritis: population based cohort study. BMJ 2011;342:d1165.

24. Pedersen AB, Baron JA, Overgaard S, et al. Short- and long-term mortality following primary total hip replacement for osteoarthritis: a Danish nationwide epidemiological study. J Bone Joint Surg Br 2011:93:172-7.

25. Maradit Kremers H, Larson DR, Noureldin M, et al. Long-Term mortality trends after total hip and knee arthroplasties: a populationbased study. J Arthroplasty 2016;31:1163-9.
26. Ministry of Health of New Zealand. Overview of the health system, 2017. Available: https://www.health.govt.nz/new-zealand-healthsystem/overview-health-system [Accessed 13 May 2019].

27. National Health Committee. Prioritising health services: a background paper for the National health Committee, 2014.

28. Ministry of Health of New Zealand. Introduction to the National clinical priority system (CPS) for access to publicly funded hip or knee joint replacement surgery. Wellington, New Zealand, 2007.

29. Chan G, Bezuidenhout L, Walker L, et al. The impact on life questionnaire: validation for elective surgery prioritisation in $\mathrm{New}$ Zealand prioritisation criteria in orthopaedic surgery. The New Zealand medical journal 2016;129:26-32.

30. Quan $\mathrm{H}$, Sundararajan V, Halfon $\mathrm{P}$, et al. Coding algorithms for defining comorbidities in ICD-9-CM and ICD-10 administrative data. Med Care 2005;43:1130-9.

31. Ministry of Health. National collections and surveys, 2017. Available: http://www.health.govt.nz/nz-health-statistics/national-collectionsand-surveys

32. Ministry of Health of New Zealand. My DHB Wellington, New Zealand, 2019. Available: https://www.health.govt.nz/new-zealandhealth-system/my-dhb [Accessed 01 Jun 2019].

33. Statistics New Zealand. Subnational population estimates tables. Wellington, New Zealand, 2017. Available: http://nzdotstat.stats.govt. nz/wbos/Index.aspx?DataSetCode=TABLECODE7512

34. Pabinger $\mathrm{C}$, Geissler A. Utilization rates of hip arthroplasty in OECD countries. Osteoarthritis and Cartilage 2014;22:734-41.

35. Hooper G, Lee AJ-J, Rothwell A, et al. Current trends and projections in the utilisation rates of hip and knee replacement in New Zealand from 2001 to 2026. N Z Med J 2014;127:82-93.

36. Elwood JM, Aye PS, Tin Tin S. Increasing disadvantages in cancer survival in New Zealand compared to Australia, between 2000-05 and 2006-10. PLoS One 2016;11:e0150734.

37. Cogon D, Kellingray $\mathrm{S}$, Inskip $\mathrm{H}$, et al. Osteoarthritis of the hip and occupational lifting. Am J Epidemiol 1998;147:523-8.

38. SN Z. New Zealand period life tables: 2012-14. Wellington, New Zeaand, 2019.

39. Barrett J, Losina E, Baron JA, et al. Survival following total hip replacement. J Bone Joint Surg Am 2005;87:1965-71.

40. Paavolainen P, Pukkala E, Pulkkinen $P$, et al. Causes of death after total hip arthroplasty: a nationwide cohort study with 24,638 patients. J Arthroplasty 2002;17:274-81. 